\title{
Infective Endocarditis in Intravenous Drug Abusers
}

\author{
José M. Miró, MD, PhD*, Asuncion Moreno, MD, PhD, \\ and Carlos A. Mestres, MD, PhD, FETCS
}

\author{
Address \\ *Infectious Diseases Service, Hospital Clinic-IDIBAPS, \\ University of Barcelona, Villarroel, I70, 08036 Barcelona, Spain. \\ E-mail: miro@medicina.ub.es \\ Current Infectious Disease Reports 2003, 5:307-316 \\ Current Science Inc. ISSN I523-3847 \\ Copyright (C) 2003 by Current Science Inc.
}

Infective endocarditis (IE) is one of the most severe complications in intravenous drug abusers (IVDA). IE usually involves the tricuspid valve, Staphylococcus aureus is the most common etiologic agent, and it has a relatively good prognosis.

Currently, between $40 \%$ and $90 \%$ of IVDA with IE are HIV infected, and the HIV epidemic has caused a decrease in the incidence of this disease, probably due to changes in drug administration habits undertaken by addicts in order to avoid HIV transmission. This review focuses on progress made over the past few years in some aspects of IE in IVDA. The pathogenesis of tricuspid endocarditis is still unknown more than 60 years after the first series. The most important advance in antibiotic therapy is that noncomplicated $S$. aureus right-sided endocarditis can be successfully treated with an intravenous 2-week course of nafcillin or cloxacillin plus an aminoglycoside, although probably the aminoglycoside administration could be stopped after the first 3 to 5 days. Surgery in HIV-infected IVDA with IE does not worsen the prognosis. Considering the possibility of reinfection in IVDA, prosthetic material is usually avoided. Tricuspid valvulectomy or valve repair should be considered the technique of choice in IVDA with right-sided IE. Replacement of the tricuspid valve by a cryopreserved mitral homograft is the latest introduction into clinical practice. It provides atrioventricular competence, thereby avoiding late right heart failure. Reinfections can be treated medically with a negligible reoperation rate. Overall mortality for HIV-infected or non-HIV-infected IVDA with IE is similar. However, among HIV-infected IVDA, mortality is significantly higher in those who are most severely immunosuppressed, with $\mathrm{CD4}^{+}$cell counts below $200 / \mu \mathrm{L}$ or with AIDS criteria.

\section{Introduction}

Infective endocarditis (IE) is one of the most severe complications of intraveous drug abuse (heroine, cocaine, or other drugs) $[1-3,4 \bullet \bullet, 5 \bullet \bullet]$. The first series of cases of IE in intravenous drug abusers (IVDA) were reported in the United States in the 1950s [1-3]. Since then, the main clinical and microbiologic features of IE in IVDA have changed very little. The tricuspid valve is the most frequently involved (70\%) (Table 1) $[1-3,4 \bullet \bullet, 5 \bullet \bullet, 6]$, and methicillinsensitive Staphylococcus aureus (MSSA) is usually the etiologic agent $(60 \%-70 \%)$ (Table 2) $[1-3,4 \bullet \bullet, 5 \bullet \bullet, 6]$. Currently, the diagnosis of IE is made according to the clinical, microbiologic, and echocardiographic criteria described by Durack et al. [7] a decade ago. The recently modified Durack criteria [ $8 \bullet$ ] have proved useful for the diagnosis of IE in IVDA [9]. Physicians from everywhere have learned that right-sided endocarditis should be always suspected in active IVDA with fever and radiologic pulmonary infiltrates, despite the absence of a significant clinical murmur. However, early diagnosis may be difficult in the febrile IVDA in the emergency room. In a recent article [10•], the use of a polymerase chain reaction (PCR) assay allowed rapid detection of bacteremia (6-7 hours) in IVDA with significant infections, including bacteremia and IE. This new PCR assay may allow early antibiotic therapy in these patients who have a high risk of bacteremia and IE.

The outcome of IE in IVDA depends on the side of the heart involved and the pathogen. The prognosis of staphylococcal right-sided endocarditis is usually good (mortality $<5 \%$, with surgery $<2 \%)[1-3,4 \bullet \bullet, 5 \bullet \bullet, 6]$. Patients with tricuspid valve vegetations greater than $2 \mathrm{~cm}$ in size $[11,12]$ and with acute respiratory distress syndrome [13] have higher mortality. Conversely, the prognosis of left-sided IE in IVDA, particularly when the aortic valve is involved, is notably worse (mortality 20\%-30\%, with surgery $15 \%-$ $25 \%)[1-3,4 \bullet \bullet, 5 \bullet \bullet, 6]$. IE caused by gram-negative bacilli or fungi has the worst prognosis. Heart failure and systemic embolization (especially to the central nervous system) are the main causes of mortality $[1-3,4 \bullet \bullet, 5 \bullet \bullet]$.

Although IE in IVDA is usually seen in urban medical centers from North America, Western Europe, or Australia $[1-3,4 \bullet \bullet, 5 \bullet \bullet]$, in the past decade a growing number of reports have come from some countries from Eastern Europe (Russia), Asia (China, Thailand, and Malaysia), South America (Brazil and Argentina), and Africa (South Africa) [14-20]. The incidence of IE among IVDA in the United States is estimated at 150 to 2000 per 100,000 
Table I. Valve involved in 1529 episodes of infective endocarditis in Spanish intravenous drug abusers (1977-1993)

\begin{tabular}{|lc|}
\hline & $n(\%)$ \\
\hline Right-sided endocarditis & $1199(79)$ \\
Tricuspid valve & $1045(68)$ \\
Pulmonic valve & $14(1)$ \\
Tricuspid and pulmonic valves & $8(<1)$ \\
Unknown & $132(9)$ \\
Left-sided endocarditis & $254(16)$ \\
Aortic valve & $103(7)$ \\
Mitral valve & $98(6)$ \\
Aortic and mitral valves & $27(1.5)$ \\
Mural/coarctation of the aorta & $3(<1)$ \\
Unknown & $24(I .5)$ \\
Mixed (right and left) endocarditis & $76(5)$ \\
\hline Data from Miró et al. [4••] and Miró et al. [6]. & \\
\hline
\end{tabular}

person-years $[2,21,22 \bullet \bullet]$, and can be higher among patients with known valvular heart disease or in cocaine addicts [23]. However, the incidence of IE in IVDA in the AIDS era is decreasing in Western countries, probably due to their inclusion in methadone programs, stopping the intravenous drug abuse, or to the changes in injection practices undertaken in order to avoid HIV transmission (less use of the parenteral route of administration, increased use of sterile needles and syringes, and less sharing of the injection paraphernalia) $[2,24]$.

This paper focuses on progress made over the past few years in the pathogenesis of right-sided IE in IVDA, antibiotic therapy for $S$. aureus right-sided IE, advances in surgery, and on the influence of HIV coinfection on the incidence, clinical and microbiologic characteristics, and outcome of this disease.

\section{Advances in the Pathogenesis}

\section{of Right-sided Infective Endocarditis}

The reason for the predominance of tricuspid valve involvement in IVDA is still unknown more than 60 years after the first reported cases [3]. The most accepted hypothesis is that endothelial damage is caused by physical "bombardment" of the tricuspid valve by impurities contained in injected drugs and/or adulterants [25]. However, several pathologic studies of tricuspid valves from IVDA who died of unrelated causes showed no such endothelial damage [2]. Attempts to reproduce tricuspid valve endocarditis in the rabbit model by injecting street heroin over several weeks, followed by intravenous challenge with a high inoculum of $S$. aureus, were unsuccessful $[2,26]$. In a recent

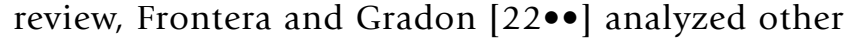
theories. Proposed hypotheses include cocaine-induced microthrombi on cardiac valves, drug-induced pulmonary hypertension with increased right-sided intracardiac turbulence, increased right-sided expression of matrix
Table 2. Etiology of infective endocarditis in intravenous drug abusers: analysis of 1529 episodes diagnosed in Spain (1977-1993)

\begin{tabular}{lc|}
\hline Organism & $\mathbf{n}(\%)$ \\
\hline Staphylococcus aureus & $1138(74)$ \\
Coagulase-negative staphylococci & $44(3)$ \\
Viridans streptococci & $94(6)$ \\
Enterococci & $21(1.5)$ \\
Other streptococci & $37(2)$ \\
Pseudomonas aeruginosa & $12(<1)$ \\
Other gram-negative aerobes & $1(<1)$ \\
Other organisms & $4(<1)$ \\
Candida species & $18(1.5)$ \\
Polymicrobial & $44(3)$ \\
Negative blood culture endocarditis & $106(7)$ \\
\hline Data from Miró et al. [4••] and Miró et al. [6]. \\
\hline
\end{tabular}

molecules capable of binding microorganisms in IVDA, the etiologic microorganism by itself, and HIV infection $[22 \bullet \bullet]$. However, the authors concluded that no single hypothesis can explain the frequency of tricuspid valve infection, and some combination of the above possibilities is probably required for developing tricuspid IE.

\section{Advances in Antibiotic Therapy}

Two-week course of combination therapy for methicillin-sensitive Staphylococcus aureus

right-sided endocarditis in intravenous drug abusers The standard therapy for MSSA endocarditis on the native valve is a 4- to 6-week course of intravenous nafcillin or cloxacillin $(8-12 \mathrm{~g} / \mathrm{d})[2,4 \bullet \bullet, 6,27,28 \bullet]$. An aminoglycoside (usually gentamicin) can be given during the first 3 to 5 days of therapy by the intravenous or intramuscular route in order to reduce the duration of fever, leukocytosis, and bacteremia [29]. If the patient is allergic to penicillin, the antibiotic treatment of choice will be a first-generation cephalosporin (cefazolin $2 \mathrm{~g} / 8 \mathrm{~h}$ intravenous) for patients without anaphylactic reactions, and vancomycin or teicoplanin for patients with anaphylactic reactions or with methicillin-resistant $S$. aureus (MRSA) strains $[2,27,28 \bullet]$. If $S$. aureus is susceptible to penicillin $\mathrm{G}(<5 \%)$, this antibiotic (12-18 MU/d intravenous) should be given instead of nafcillin or cloxacillin for the same period of time $[2,27,28 \bullet]$.

However, the duration of therapy for right-sided MSSA IE can be considerably shortened. This is feasible because the in vivo models of IE have shown that the density of bacteria in right-sided vegetations is smaller than on the left side [30], the time required to sterilize valve vegetations is reduced to one half with nafcillin or cloxacillin plus an aminoglycoside in comparison with a penicillin alone [31,32], and clinically the prognosis of right-sided endocarditis is very good $[1-3,4 \bullet \bullet, 5 \bullet \bullet, 6]$. These data provided the rationale for testing short-course therapy for right-sided endocarditis caused by MSSA. 
Table 3. Published studies with nafcillin or cloxacillin plus an aminoglycoside, cloxacillin alone, or vancomycin or teicoplanin plus an aminoglycoside during $\mathbf{2}$ weeks for methicillin-sensitive Staphylococcus aureus right-sided infective endocarditis in intravenous drug abusers

\begin{tabular}{|c|c|c|c|c|c|}
\hline Study & Therapy & Number & Cures, $n$ & Failures/relapses, $n / n$ & Deaths, $n$ \\
\hline Chambers et al. [33] & $\mathrm{Naf}+\mathrm{Tob}$ & 50 & 47 & $0 / 3$ & 0 \\
\hline Espinosa et al. [34] & $\mathrm{Clo}+\mathrm{Gen}$ & 12 & 12 & $0 / 0$ & 0 \\
\hline Torres-Tortosa et al. [35] & $\mathrm{Clo}+\mathrm{Amk}$ & 72 & 67 & $4 / 0$ & 1 \\
\hline Miró [26] & Clo + Gen & 20 & 19 & $0 / 1$ & 0 \\
\hline Fortún et al. [36] & $\mathrm{Clo}+\mathrm{Gen}$ & 8 & 7 & $1 / 0$ & 0 \\
\hline Ribera et al. [37] & $\mathrm{Clo}+\mathrm{Gen}$ & 36 & 31 & $2 / 1$ & 2 \\
\hline Fortún et al. [38••] & Clo + Gen & II & II & $0 / 0$ & 0 \\
\hline Total & & 209 & 194(93\%) & $7 / 5(6 \%)$ & $3(1 \%)$ \\
\hline Ribera et al. [37] & Clo alone & 38 & 34 & $3 / 0$ & 1 \\
\hline Total & & 38 & $34(89 \%)$ & $3 / 0(8 \%)$ & $\mathrm{I}(2.5 \%)$ \\
\hline Chambers et al. [33] & Van + Tob & 3 & 1 & $1 / 1 /$ & 0 \\
\hline \multirow{2}{*}{ Fortún et al. [38••] } & $\operatorname{Van}+$ Gen & 10 & 6 & $3 / 1$ & 0 \\
\hline & Tei + Gen & 10 & 7 & $1 / 2$ & 0 \\
\hline Total & & 23 & $14(61 \%)$ & $5 / 4(39 \%)$ & 0 \\
\hline
\end{tabular}

In 1988 Chambers et al. [33] published the first study showing the efficacy of a 2-week course of nafcillin plus tobramycin for the therapy of right-sided MSSA endocarditis in IVDAs. Ninety-four percent of the 50 patients treated were cured with this regimen. Table 3 summarizes the studies published between 1988 and 2001 [26,34-37,38••] with a 2-week course of nafcillin or cloxacillin plus an aminoglycoside (usually gentamicin) for the therapy of noncomplicated right-sided MSSA endocarditis in IVDAs. Overall, 209 patients have been treated, with an overall cure rate of greater than $90 \%$. There were only seven failures during the treatment, including five relapses; only three patients died.

Some studies suggest that it may not be necessary to administer an aminoglycoside during 2 weeks. In a descriptive study, Miró et al. [39] had the opportunity to follow 10 IVDA with right-sided $S$. aureus endocarditis who left the hospital against medical advice before finishing the 4 weeks of treatment, having received 10 to 14 days of cloxacillin but only 1 week of gentamicin. All patients were cured without relapses or deaths after a follow-up period ranging between 3 to 18 months. Ribera et al. [37] recently demonstrated that a regimen of 2 weeks of monotherapy with cloxacillin was as effective as the combination therapy with cloxacillin plus gentamicin for treating right-sided MSSA IE. The rate of cures for the arm of cloxacillin alone was almost $90 \%$. These data suggest that for right-sided MSSA endocarditis, the addition of an aminoglycoside is not essential. However, its addition for the first 3 to 5 days of therapy may have some therapeutic value due to its synergistic effect with penicillinase-resistant penicillins $[27,28 \bullet 29]$.

Conversely, it is important to remember that drug addicts with MSSA right-sided IE treated with vancomycin or teicoplanin combined with an aminoglycoside during 2 weeks (Table 3 ) or given alone during 4 weeks $[33,38 \bullet \bullet, 40]$ have an unacceptable rate of failures. Furthermore, adverse events (rash or nephrotoxicity) are not unusual. This is the same for left-side involvement and for MRSA infections [28•]. Lodise et al. [41] studied the prognostic factors of mortality in 98 IVDA with $S$. aureus native valve IE diagnosed in Detroit from 1997 through 2001. The IE was rightsided in $67 \%$ of patients and caused by MRSA in $14 \%$ of episodes. A $\beta$-lactam antibiotic or vancomycin was the empiric treatment in 45 and 39 patients, respectively. In the multivariate analysis, vancomycin therapy was an independent predictor of mortality (odds ratio [OR], 3.2 [1.0-10.8]) and was associated with slower response and longer bacteremia compared with $\beta$-lactams [41]. There are several reasons to explain the failures of MSSA endocarditis in IVDA treated with glycopeptides: 1) glycopeptides are less rapidly bactericidal against MSSA compared with penicillinase-resistant penicillins [40]; 2) glycopeptides have a poor diffusion into the valve vegetations $(e g$, teicoplanin has a peripheral pattern) [42]; and 3) the renal clearance of glycopeptides in IVDA is greater than in healthy volunteers [43]. For these reasons, IVDA with IE treated with these drugs should be closely monitored in order to check the effectiveness of the treatment. Therefore, vancomycin or teicoplanin should be used only in patients with allergy to penicillin and must be given for at least 4 weeks, plasma serum levels should be monitored often, and gentamicin should be added during the first 1 to 2 weeks of therapy.

Exclusion criteria for 2-week course of combination therapy for methicillin-sensitive Staphylococcus aureus right-sided endocarditis in intravenous drug abusers The standard 4-week regimen must be used in the following situations: 1) slow clinical or microbiologic response (> 96 hours) to the initial antibiotic therapy $[28 \bullet 44]$; 
2) complicated right-sided endocarditis: presence of right heart failure, valve vegetations greater than $2 \mathrm{~cm}$ in diameter, acute respiratory failure, empyema, or septic metastatic foci outside the lungs or extracardiac complications $(\mathrm{eg}$, renal failure) $[11,12,28 \bullet]$; 3 ) therapy with antibiotics other than penicillinase-resistant penicillins $(e g$, first-generation cephalosporins, glycopeptides) $[36,38 \bullet \bullet, 40,44]$; 4) rightsided endocarditis caused by MRSA or polymicrobial infections; 5) IVDA with severe immunosuppression $(<200$ $\mathrm{CD} 4$ cells $/ \mu \mathrm{L}$ ) or AIDS.

\section{Other antibiotic treatments for right-sided} methicillin-sensitive Staphylococcus aureus endocarditis in intravenous drug abusers

Right-sided S. aureus endocarditis in IVDA can be successfully treated with ciprofloxacin plus rifampin given by the oral route [45,46]. Heldman et al. [46] demonstrated that oral antibiotic treatment with ciprofloxacin plus rifampin during 4 weeks was as effective as the recommended 4-week regimen with oxacillin plus gentamicin. This oral regimen may be a reasonable alternative to parenteral therapy in some patients. However, it should be taken into account that resistance to one or both drugs during treatment has been described, and an important pharmacokinetic interaction between rifampin and methadone exists.

\section{Advances in the Surgical \\ Treatment of Infective Endocarditis in Intravenous Drug Abusers}

Surgery for IE continues to be a challenge regardless of the valve involved $[47,48]$. In the case of HIV-infected IVDA, this is a particularly serious issue for the following special circum-

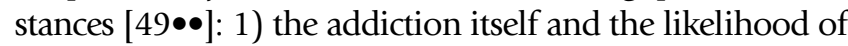
continuing the addiction after surgery, including the continuous risk of recurrent IE throughout the follow-up, and the continuous risk of overdose and other drug-related complications; 2) the HIV-infection; and 3) social issues regarding drug addiction and HIV infection.

It is true that IE in IVDA has to be initially approached in the same way as in the general population, from diagnosis to medical and surgical therapy. However, it is also true that drug addiction has represented a stigma for many years and surgery has been denied to IVDA and to HIVinfected patients based on ignorance, unclear data on results, lack of immunologic and virologic data, postoperative reinfection rate, and follow-up [49••]. Our knowledge today suggests that neither drug abuse nor HIV infection are contraindications for surgery [44]. Currently, there are effective detoxification programs for IVDA, and the prognosis of HIV infection has dramatically improved with the introduction of highly active antiretroviral therapy (HAART) [49••]. On the other hand, the risk of HIV transmission to health care professionals ("operative team") has been minimized with the standard practice of "universal precautions" and the effective postexposure prophylaxis regimens with antiretroviral therapy [49••]. This reason should never enter in the decision-making process.

Accumulated experience in the form of scanty reports including short series suggest that surgery can be carried out in HIV-infected IVDA with acceptable results in terms of early and late morbidity and mortality $[49 \bullet \bullet, 50-55]$. Some reports represent the cooperative task of several institutions on a retrospective basis [50,52]; however, the information provided is useful to assess the outcome of this special subset of patients [49••]. Mathew et al. [56] studied a cohort of 80 IVDA who underwent several types of operations for IE. The probability of survival at 3 and 5 years was $74 \%$ and $70 \%$, respectively, and these figures are comparable to the general population undergoing surgery for IE. Arbulu et al. [57], in a cohort of 54 IVDA undergoing surgery for right-sided IE, found a survival rate of $64 \%$ at 22 years. Aris et al. [53] studied 40 HIV-infected patients (mostly IVDA with IE) undergoing cardiopulmonary bypass, and the probability of survival at 1,3 , and 5 years was $70 \%, 60 \%$, and $48 \%$, respectively. These studies were performed before the HAART era (before 1996) and currently the HIV prognosis with HAART is much better. At our institution [58•], we have been able to determine that the overall 10-year actuarial survival for all HIV patients undergoing major cardiac surgery is $58 \%$, and in the subgroup of HIV IVDA the survival extends up to $48 \%$. After 10 years the survival is roughly the same; however, the number of patients is very small.

\section{Left-sided infective endocarditis}

From a practical standpoint the indications and technical options in the case of left-sided IE are the same as in the general population, and this applies to native and prosthetic IE. There is a trend toward a radical management of the complicated aortic root, namely in the presence of abscesses or fistulae. Aortic root replacement with a homograft (antibiotic-preserved or cryopreserved) as described by Donaldson and Ross [59] seems to be a good option in cases with a complicated annulus with low reoperation rate in the long-term. This has recently been readdressed by Yankah et al. [60•] in an elegant report.

\section{Right-sided infective endocarditis}

The tricuspid valve is the most commonly involved (Table 1) $[1-3,4 \bullet \bullet, 5 \bullet \bullet, 6]$. Pulmonary valve involvement is exceptional. In our experience, we have operated on seven patients in the past 20 years with tricuspid IE, with only one case of pulmonary valve IE in an IVDA who underwent pulmonary valvulectomy and replacement of the pulmonary root with a pulmonary homograft. We found this to be a good surgical option [48]. Medical therapy is able to control the infection in the majority of cases, and therefore just a handful of patients may require surgery as a last resort.

\section{Indications for surgery on the right heart}

Indications are based on anatomic, clinical, and microbiologic criteria, considering two main indications for surgery in right-sided IE in IVDA: 1) patients with vegetations 
larger than $2 \mathrm{~cm}$, right heart failure, and recurrent pulmonary emboli $[11-13,30]$; and 2) fungal endocarditis or IE caused by other pathogens difficult to eradicate, and persistent or recurrent bacteremia despite optimal antimicrobial therapy for more than 7 days (eg, S. aureus, Pseudomonas aeruginosa) $[2,4 \bullet \bullet, 5 \bullet \bullet, 47,48]$.

In addition, surgery on the tricuspid valve may be indicated in patients with cured IE but who present with uncontrollable right heart failure because of severe involvement of the valve during the follow-up.

\section{Technical options in right-sided infective endocarditis}

Presently the need for tricuspid valve replacement in the general population is almost exceptional. In the case of IE, medical therapy achieves the best results, and just a handful of patients will require operative treatment. In these cases, there are some technical options that have been tested in the past.

\section{Tricuspid valvulectomy without prosthetic replacement}

Tricuspid valvulectomy without prosthetic replacement was advocated by Arbulu et al. [61] in 1971 as a life-saving maneuver. It has been shown that it is an effective form of therapy since it achieves cure of the infection and avoids recurrent or relapsing endocarditis because there is no valve left in place. Leaving the patient without right atrioventricular competence carries a significant risk of late right heart failure that will eventually require valve replacement. Current estimates on the order of $15 \%$ or higher take into account valve replacement and the associated problem of impairment of the right ventricular function $[57,61,62]$.

\section{Vegetectomy and/or tricuspid valve repair}

Although a relatively old technique, vegetectomy can seldom be performed on an isolated vegetation without additional damage to the tricuspid valve [63]. Very recently vegetectomy under inflow occlusion [64] has been advocated as a safe alternative to treat isolated vegetations of the tricuspid valve. The experience reported by Raman et al. [64] seems to be of interest in selected cases considering the limitations of this technique. Inflow occlusion consists of a temporary occlusion of the venous return by using slings, thus allowing the surgeon to open the right atrium for a quick exploration of the right heart. As the heart continues to beat, it will be empty within seconds as blood pumps into the pulmonary tree. Simple vegetectomy can be carried out under these conditions. The right atrium can be immediately closed and blood will again fill up the right heart. There were no mortalities in this study [64], and the results can be considered encouraging. However, the longest period of inflow occlusion was 2 minutes, and therefore this is a major limiting factor for more complex procedures.

We do not consider a vegetation alone as an isolated indication for surgery unless some other criteria apply like persistent sepsis or recurrent pulmonary emboli despite aggressive medical therapy. Tricuspid valve repair should be considered as the technique of choice in any of its modalities, from partial leaflet resection to chordal transposition with or without annuloplasty [65-68]. It is our belief that prosthetic rings should ideally be avoided in the case of active IE of the tricuspid valve. The already old but worldwide tested De Vega annuloplasty is probably well indicated in this setting, as it provides valvular competence without foreign material [69]. The experience reported in the literature with tricuspid valve repair in IE is still scanty, even though the results are satisfactory.

\section{Tricuspid valve replacement with mechanical}

valves or bioprostheses

In the case of IVDA, mechanical valves should be avoided. The rationale is the risk of fatal or nonfatal accidents due to a badly controlled anticoagulation therapy or simply because of the lack of compliance of the IVDA [57]. Furthermore, persistent addiction to parenteral drugs favors prosthetic valve endocarditis. There is almost no information in the literature regarding the performance of mechanical versus biologic valves implanted in the tricuspid position in IDVA for endocarditis, but data extrapolated from the general population indicate that both types of replacement devices perform similarly, including morbidity and mortality rates in the early postoperative period and also in the long term. The use of bioprostheses in the tricuspid position is not free from thrombotic complications $[70,71]$.

\section{Tricuspid valve replacement with cryopreserved mitral homografts}

This has emerged as the latest technical option for tricuspid valve replacement. In this case the rationale is to completely avoid implantation of foreign material [57,72]. Bioprostheses have a polyester sewing ring that is potentially infectable and they are not free from complications like pannus [71]. The reported experience so far refers to small groups of IVDA suffering from a variety of types of endocarditis since the initial report in 1993 by Pomar and Mestres [73]. The operation is conceptually and practically simple and provides competence of the right atrioventricular orifice, thus eventually avoiding late right heart failure due to persistent massive tricuspid regurgitation. The review of the literature produces short series and case reports that tend to conclude that the use of cryopreserved mitral homografts in IE achieves complete cure of the infection and provides valve competence $[74,75 \bullet \bullet, 76]$. The longest follow-up available is just turning into the tenth year and shows that several degrees of valve competence can be observed on routine serial echocardiography studies but without development of right heart failure [74]. Patients require limited medication like diuretics. On the other hand, a constant in the IVDA population, persistent addiction, dictates the appearance of new episodes of endocarditis, but the main difference is that medical therapy is possible, reliable, and effective. 
Table 4. Intravenous drug abusers with tricuspid endocarditis who underwent cryopreserved mitral homograft implanted into the tricuspid position at the Hospital Clinic of Barcelona since I99 I

\begin{tabular}{|c|c|c|c|c|c|c|}
\hline Year & Etiology & $\begin{array}{l}\text { HIV } \\
\text { stage* }\end{array}$ & $\begin{array}{c}\text { Follow-up } \\
\text { years }\end{array}$ & $\begin{array}{l}\text { Drug addiction/ } \\
\text { relapse }\end{array}$ & $\begin{array}{l}\text { Recurrent infective } \\
\text { endocarditis }\end{array}$ & Outcome \\
\hline |991 & $\begin{array}{l}\text { Polymicrobial } \\
\text { (Candida albicans) }\end{array}$ & $\mathrm{A} 3$ & II & Yes & $\begin{array}{c}\text { Corynebacterium } \\
\text { species }\end{array}$ & Alive, no reoperation \\
\hline 1991 & $\begin{array}{l}\text { Polymicrobial } \\
\text { (Candida tropicalis) }\end{array}$ & $\mathrm{Al}$ & II & Yes & MSSA & Alive, no reoperation \\
\hline 1992 & MSSA & $\mathrm{A} 2$ & 10 & No & No & Alive, no reoperation \\
\hline 1994 & MSSA & A3 & I & Yes & No & Death, overdose \\
\hline 1996 & MSSA & $\mathrm{A} 2$ & 7 & Yes & $\begin{array}{c}\text { MSSA, } \\
\text { Streptococcus mitis }\end{array}$ & Alive, no reoperation \\
\hline 2001 & Brucella species & $\mathrm{A} 3$ & 0 & No & Not applicable & Postoperative death, sepsis \\
\hline
\end{tabular}
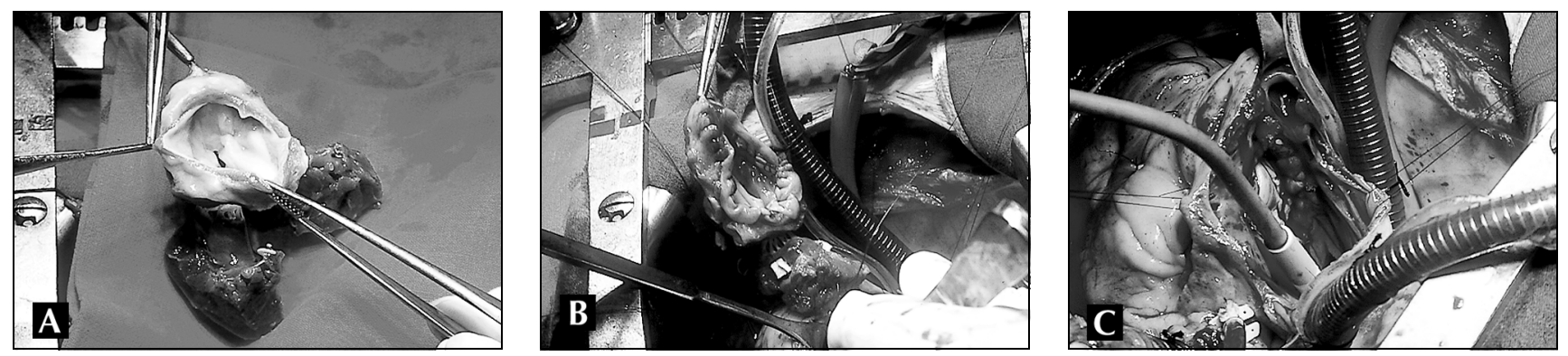

Figure 1. Surgical technique of mitral homograft implantation. A, Cryopreserved mitral homograft after thawing, ready to be implanted into tricuspid position in an intravenous drug abuser with right-sided endocarditis. B, The mitral homograft during the implantation. Sutures are placed through the papillary muscles. C, The completed operation. The right atrium is still open, and bulging of the anterior leaflet of the mitral homograft can be seen.

One question that may arise is why not use tricuspid instead of mitral homografts. The reply is simple. The tricuspid valve is much more delicate than the mitral complex, the leaflets being very thin. In addition, the anatomy of the tricuspid valve is subjected to interindividual variability that usually involves the papillary muscles that may differ in number and shape. The tricuspid valve is also difficult to harvest and extreme care always must be taken with the harvesting technique.

\section{Personal experience}

At our institution we have treated six patients with a cryopreserved mitral homograft implanted into the tricuspid position since 1991 [73,74,75••] (Table 4). The original description of the surgical technique was based on the simple concept of implanting a human valve at the atrioventricular level (Fig. 1). We advocate the elimination of foreign material like annuloplasty rings or bands and implanting the homograft with just an annular reinforcement band made from the patient's own pericardium. Miyagishima et al. [76] have slightly modified the technique of anchoring the papillary muscles through the right ventricular free wall trying to reduce the rate of late tricuspid regurgitation.

Our experience shows that surgery on the tricuspid valve in IVDA can be performed with an acceptable risk, as we only experienced one case of perioperative death in a young female patient with a CD4 count below 200/ $\mathrm{mm}^{3}$. She died 4 weeks after surgery because of Salmonella sepsis. Follow-up extended 10 years showed recurrence of endocarditis due to persistent addiction in three patients. There were also three patients with echocardiographic evidence of moderate to severe tricuspid regurgitation but with no clinical evidence of severe heart failure.

\section{Influence of HIV-1 Infection in}

\section{Endocarditis in Intravenous Drug Abusers}

Currently, the prevalence of HIV-1 infection among IVDA with IE ranges between $40 \%$ and $90 \%$ [36,37, 46 , $77,78,79 \bullet \bullet, 80]$. However, the full consequences of HIV infection in IE in IVDA are not yet fully known because only a few studies have been published $[52,77,78$, $79 \bullet \bullet, 80]$. The main conclusions from the literature review are discussed below.

\section{Incidence}

Several epidemiologic studies $[21,81,82]$ have shown that HIV infection is associated with a several-fold increased risk of endocarditis in IVDA. Manoff et al. [81] showed that compared with HIV-negative IVDA, HIV-infected IVDA with 
Table 5. Mortality from infective endocarditis in HIV-infected intravenous drug abusers according to the HIV stage or the level of immunosuppression

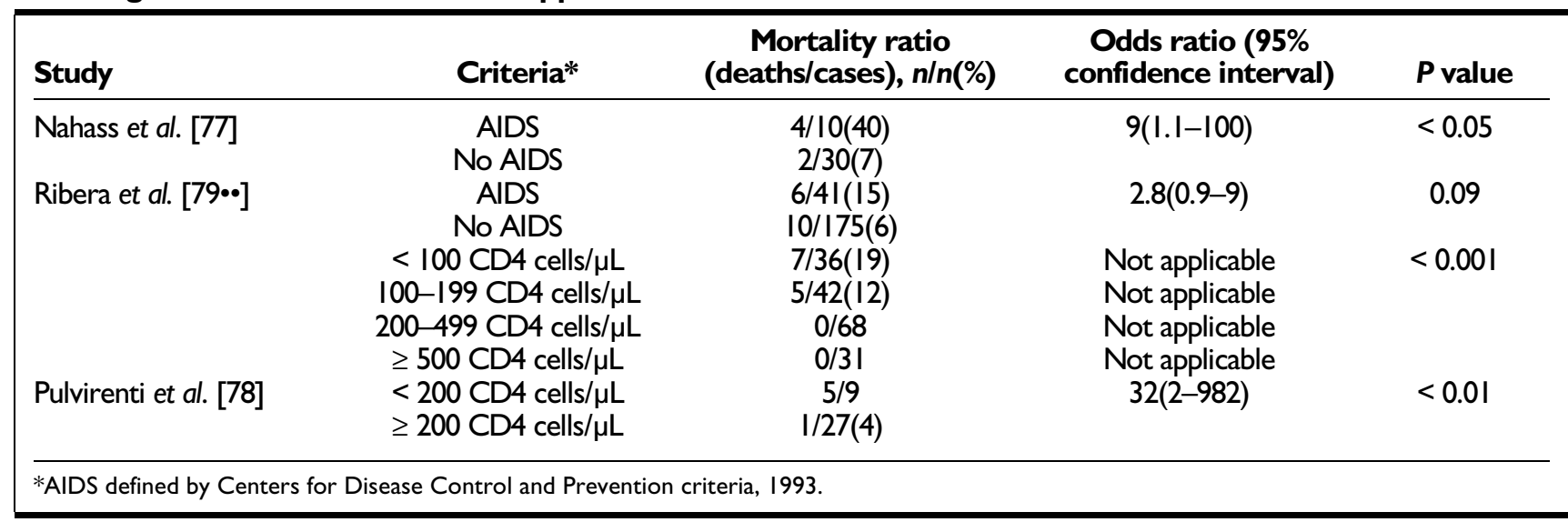

CD4 cell counts 350 cells $/ \mu \mathrm{L}$ or more had an OR of 2.31 (0.61-8.8) for developing IE, whereas those with a CD4 cell count below 350 cells/ $\mu \mathrm{L}$ had an OR of $8.31(1.2-56)$ for developing IE. These findings have been confirmed by Wilson et al. [83•]. IE incidence was higher among HIV-infected than HIV-seronegative IVDA (13.8 vs 3.3 cases/1000 personyears), and multivariate analysis of HIV-infected patients revealed an inverse association between IE and CD4 lymphocyte count (OR for 200-499 cells $/ \mu \mathrm{L}, 2.01$ [0.95-4.25]; OR for $<200$ cells $/ \mu \mathrm{L}, 3.61$ [1.52-8.59]). Other variables associated with an increased risk of IE were female gender (OR, 3.26 [1.73-6.14]), IVDA with increasing injection use frequency (OR for at least daily use of 6.07 [2.71-13.56]), and patients with prior IE (OR, 4.93 [1.44-16.85]). Conversely, IVDA with alcohol intake had a decreased risk of IE [83•]. The risk in HIV-infected patients who do not abuse drugs is not increased [84•]. Human T-cell lymphotrophic virus II (HTLV II) infection has no influence on the risk of IE [85].

Clinical characteristics and etiology

HIV infection does not alter the febrile response of IVDA patients with IE [86]. However, HIV-infected patients have lower white blood cell counts $[78,79 \bullet \bullet, 80]$ and a higher ratio of right-sided endocarditis and $S$. aureus infections than HIV-negative IVDA [78,79••]. Conversely, HIV-negative IVDA had a higher ratio of left-sided IE and streptococcal infections $[79 \bullet \bullet, 80]$.

\section{Antibiotic therapy}

Response to antibiotic therapy is similar among HIV-

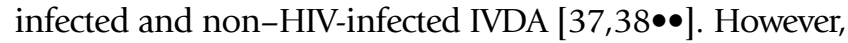
we do not know if right-sided MSSA endocarditis can be successfully treated with a short-course of therapy in HIVinfected IVDA. Ribera et al. [37] and Fortún et al. [38••] showed that the cure rates for asymptomatic HIV-infected IVDA were the same as for HIV-negative IVDA $(90 \%$ and $100 \%$, respectively). In both studies, HIV-infected IVDA had a mean/median CD4 cell count of about $300 / \mu \mathrm{L}$. Although these data are very promising, the reality is that we do not have enough information about the efficacy of this short-course regimen in AIDS or severely immunosuppressed patients (CD 4 cell counts $<200 / \mu \mathrm{L}$ ), the subgroups of HIV-infected patients with the highest rates of mortality $[77,78,79 \bullet \bullet]$. Therefore, it seems prudent to treat these patients with the more active antibiotic regimens during 4 weeks.

\section{Surgery}

Cardiac surgery in HIV-infected IVDA with IE, as we have explained earlier, does not worsen the endocarditis or the HIV infection prognosis $[49 \bullet \bullet, 52,53]$.

\section{Prognosis}

Overall mortality between HIV-infected and non-HIVinfected IVDA with IE is similar $[77,78,79 \bullet \bullet]$. However, in HIV-infected IVDA with endocarditis, several studies have demonstrated that the AIDS stage and severe immunosuppression (CD4 cell counts $<200 / \mu \mathrm{L}$ ) worsen the prog-

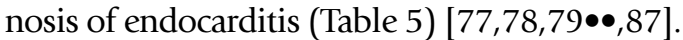

Finally, opportunistic infections related to AIDS should also be considered in HIV-1-infected IVDA with endocarditis because drug addicts may have multiple simultaneous infections, and the diagnostic work-up may be difficult in these circumstances.

\section{Conclusions}

The clinical and microbiologic picture of IE in IVDA have changed very little over time. The tricuspid valve is the most frequently involved, $S$. aureus is usually the etiologic agent, and the prognosis is relatively good. HIV-infection is detected in $40 \%$ to $90 \%$ of IVDA with IE, increasing the risk of IE. However, the incidence of IE in IVDA has decreased in Western countries. Noncomplicated MSSA right-sided IE can be successfully treated with a 2-week course regimen of nafcillin or cloxacillin plus an aminoglycoside. Conservative techniques can be used in the surgical treatment of right-sided IE, although the use of cryopreserved mitral homografts for 
tricuspid valve replacement seems to be a reliable alternative to eradicate disease. Overall mortality for HIV-infected or non-HIV-infected IVDA with IE seems to be similar. However, among HIV-infected IVDA, mortality is significantly higher in those who are most severely immunosuppressed.

\section{Acknowledgments}

The authors thank Maria Antonia Rodriguez Jové for her technical assistance. Dr. José M. Miró was a recipient of a research grant from the Institut d'Investigacions Biomèdiques August Pi I Sunyer (IDIBAPS), Barcelona, Spain.

\section{References and Recommended Reading}

Papers of particular interest, published recently,

have been highlighted as:

- Of importance

- Of major importance

1. Sheagren JN:Endocarditis complicating parenteral drug abuse. In Current Cinical Topics in Infectious Diseases. Edited by Remington JS, Swartz MN. New York: McGraw-Hill; 1981:211-233.

2. Sande MA, Lee BL, Millills J, Chambers HF: Endocarditis in intravenous drug users. In Infective Endocarditis, edn 2. Edited by Kaye D. New York: Raven Press; 1992:345-359.

3. Cherubin CE, Sapira JD: The medical complications of drug addiction and the medical assessment of the intravenous drug user: 25 years later. Ann Intern Med 1993, 119:1017-1028.

4.• Miró JM, del Rio A, Mestres CA: Infective endocarditis in itravenous drug abusers and HIV-1 infected patients. Infect Dis Clin North Am 2002, 16:273-295.

This article reviews the epidemiology, clinical characteristics, diagnosis, prognosis, and surgery of IE in IVDA, analyzes the role of HIV infection in the clinical picture and outcome of IE in IVDA, and reviews all cases published of IE in HIV-infected patients who were not IVDA.

$5 . \bullet$ Brown PD, Levine D: Infective endocarditis in the injection drug user. Infect Dis Clin North Am 2002, 16:645-655.

This article updates the pathophysiology, microbiology, clinical presentation, complications, laboratory findings, and treatment of IE in IVDA.

6. Miró JM, Cruceta A, Gatell JM: Infective endocarditis (IE) in Spanish I.V. drug addicts (IVDA): analysis of 1529 episodes (1978-1993) [abstract-109: 32.36]. In 3rd International Symposium on Modern Concepts in Endocarditis. Boston: July 13-15, 1995.

7. Durack DT, Lukes AS, Bright DK, Duke Endocarditis Service: New criteria for diagnosis of infective endocarditis: utilization of specific echocardiographic findings. Am J Med 1994, 96:200-209.

8. Li JS, Sexton DJ, Mick N, et al.: Proposed modifications to the Duke criteria for the diagnosis of infective endocarditis. Clin Infect Dis 2000, 30:633-638.

The recently modified Durack criteria are useful for the diagnosis of IE in IVDA.

9. Palepu A, Cheung SS, Montessori V, et al.: Factors other than the Duke criteria associated with infective endocarditis among injection drug users. Clin Invest Med 2002, 25:118-125.

10. Rothman RE, Majmudar MD, Kelen GD, et al:: Detection of bacteremia in emergency department patients at risk for infective endocarditis using universal 16S rRNA primers in a decontaminated polymerase chain reaction assay. J Infect Dis 2002, 186:1677-1681.

This article describes the use of a PCR assay that allowed rapid detection of bacteremia (6-7 hours) in IVDA with significant infections, including bacteremia and IE.

11. Hecht SR, Berger M: Right-sided endocarditis in intravenous drug users. prognostic features in 102 episodes. Ann Intern Med 1992, 117:560-566.
12. Martin-Davila P, Fortun J, Navas E, et al.: Analysis of mortality and risk factors associated in native valve endocarditis in drug users: the importance of vegetation size [abstract: L-762]. In 42nd Interscience Conference on Antimcrobial Agents and Chemotherapy (ICAAC) Abstracts, American Society for Microbiology. San Diego: September 27-30, 2002.

13. Torres-Tortosa M, González M, Pérez E, et al.: Endocarditis infecciosa en heroinónamos en la provincia de Cádiz. Un estudio multicéntrico sobre 150 episodios. Med Clin (Barc) 1992, 98:521-526.

14. Demin AA, Drobysheva VP, Vel'ter Olu: Infectious endocarditis in intravenous drug abusers. Klin Med (Mosk) 2000, 78:47-51.

15. Zou Q, Hu P, Jiang Y: Characteristics and treatment of Staphylococcus endocarditis. Zhonghua Nei Ke Za Zhi 1996, 35:455-457.

16. Yoong KY, Cheong I: A study of Malaysian drug addicts with human immunodeficiency syndrome. Int J STD AIDS 1997, 8:118-123.

17. Thamlikitkul V, Praditsuwan R, Permpikul C, Jootar P: Native valve infective endocarditis at Siriraj Hospital, 1982-1989. J Med Assoc Thai 1991, 74:313-322.

18. Ruiz E, Schirmbeck T, Figueiredo LT: A study of infectious endocarditis in Ribeirao Preto, SP-Brazil. Analysis of cases occurring between 1992 and 1997. Arq Bras Cardiol 2000, 74:217-231.

19. De Rosa A, Botvinik G, Kaufman S, Rigou D: Endocarditis infecciosa y drogadicción. Medicina (Buenos Aires) 1994, 54:193-198.

20. Williams PG, Ansell SM, Milne FJ: Illicit intravenous drug use in Johannesburg-medical complications and prevalence of HIV infection. S Afr Med J 1997, 87:889-891.

21. Spijkerman IJ, van Ameijden EJ, Mientjes GH, et al.: Human immunodeficiency virus infection and other risk factors for skin abscesses and endocarditis among injection drug users. J Clin Epidemiol 1996, 49:1149-1154.

$22 . \bullet$ Frontera JA, Gradon JD: Right-side endocarditis in injection drug users: review of proposed mechanisms of pathogenesis. Clin Infect Dis 2000, 30:374-379.

This excellent article reviews and proposes several pathogenetic mechanisms in order to explain the high prevalence of right-sided endocarditis in IVDA.

23. Chambers HF, Morris DL, Täuber MG, Modin G: Cocaine use and the risk of endocarditis in intravenous drug abusers. Ann Intern Med 1987, 106:833-836.

24. Torres-Tortosa M, Rivero A, de Alarcon A, et al.: Decrease in the annual frequency of infectious endocarditis among intravenous drug users in southern Spain. Enferm Infect Microbiol Clin 2000, 18:293-294.

25. Cannon NJ, Cobbs CG: Infective endocarditis in drug addicts. In Infective Endocarditis. Edited by Kaye D. Baltimore: University Park Press; 1976:111-127.

26. Miró JM: Endocarditis infecciosa en drogadictos: estudio epidemiológico, clínico y experimental. Universidad de Barcelona: Tesis doctoral; 1994.

27. Wilson WR, Karchmer AW, Dajani AS, et al.: Antibiotic treatment of adults with infective endocarditis due to streptococci, enterococci, staphylococci and HACEK microorganisms. JAMA 1995, 274:1706-1713.

28. Rubinstein E, Carbon C , and the Endocarditis Working Group of the International Society of Chemotherapy: Staphylococcal endocarditis - recommendations for therapy. Clin Microbiol Infect 1998, 4:3S27-3S33.

The standard therapy for MSSA endocarditis on the native valve is a 4- to 6-week course of intravenous nafcillin or cloxacillin (8-12 g/d).

29. Korzeniowski O, Sande MA, The National Collaborative Endocarditis Study Group: Combination antimicrobial therapy for Staphylococcus aureus endocarditis in patients addicted to parenteral drugs and in nonaddicts: a prospective study. Ann Intern Med 1982, 97:496-503. 
30. Bayer AS, Norman DC: Valve-site specific pathogenic differences between right-sided and left-sided bacterial endocarditis. Chest 1990, 98:200-205.

31. Sande MA, Johnson ML: Antimicrobial therapy of experimental endocarditis caused by Staphylococcus aureus. J Infect Dis 1975, 131:367-375.

32. Sande MA, Courtney KB: Nafcillin-gentamicin synergism in experimental staphylococcal endocarditis. J Lab Clin Med 1976, 88:118-124.

33. Chambers HF, Miller T, Newman MD: Right-sided Staphylococcus aureus endocarditis in intravenous drug abusers: two-week combination therapy. Ann Intern Med 1988, 109:619-624.

34. Espinosa FJ, Valdes M, Martín Luengo M, et al:: Right-sided endocarditis caused by Staphylococcus aureus in parenteral drug addicts: evaluation of a combined therapeutic scheme for 2 weeks versus conventional treatment. Enferm Infect Microbiol Clin 1993, 11:235-240.

35. Torres-Tortosa $\mathrm{M}$, de Cueto $\mathrm{M}$, Vergara A, et al.: Indications and therapeutic results of an antibiotic regimen lasting two weeks in intravenous drug users with right-sided S. aureus infective endocarditis: a multicentre study of 139 consecutive cases. Eur J Clin Microbiol Infect Dis 1994, 13:533-534.

36. Fortún J, Pérez-Molina JA, Añón MT, et al.: Right-sided endocarditis caused by Staphylococcus aureus in drug abusers. Antimicrob Agents Chemother 1995, 39:525-528.

37. Ribera E, Gómez V, Cortes E, et al.: Effectiveness of cloxacillin with or without gentamicin in short-term therapy for rightsided Staphylococcus aureus endocarditis: a randomized, controlled trial. Ann Intern Med 1996, 125:969-974.

38.• Fortún J, Navas E, Martínez-Beltrán J, et al:: Short-course therapy for right-side endocarditis due to Staphylococcus aureus in drug abusers: cloxacillin versus glycopeptides in combination with gentamici. Clin Infect Dis 2001, 33:120-125.

This is the latest randomized clinical trial to compare the efficacy and safety of a 2-week course of cloxacillin plus gentamicin versus vancomycin plus gentamicin versus teicoplanin plus gentamicin in IVDA with right-sided $S$. aureus endocarditis. The main conclusion is that the glycopeptide-containing combinations are ineffective and are associated with adverse events.

39. Miró JM, Gatell JM, Pujadas R, et al.: Right-sided endocarditis with Staphylococcus aureus. Ann Intern Med 1989, 110:497-498.

40. Small PM, Chambers HF: Vancomycin for Staphylococcus aureus endocarditis in intravenous drug abusers. Antimicrob Agents Chemother 1990, 34:1227-1231.

41. Lodise TP, Mckinnon PS, Levine DP, Rybak MJ: Predictors of mortality and impact of initial therapy on outcomes in intravenous drug users (IVDU) with Staphylococcus aureus (SA) infective endocarditis (IE) [abstract: L-765]. In 42nd Interscience Conference on Antimcrobial Agents and Chemotherapy (ICAAC) Abstracts, American Society for Microbiology. San Diego: September 27-30, 2002.

42. Cremieux AC, Maziere B, Vallois JM, et al.: Evaluation of antibiotic difussion into cardiac vegetations by quantitative autoradiography. J Infect Dis 1989, 159:938-944.

43. Rybak MJ, Albrecht LM, Berman JR, et al.: Vancomycin pharmacokinetics in burn patients and intravenous drug abusers. Antimicrob Agents Chemother 1990, 34:792-795.

44. DiNubile MJ: Short-course antibiotic therapy for right-sided endocarditis caused by Staphylococcus aureus in injection drug users. Ann Intern Med 1994, 121:873-876.

45. Dworkin RJ, Sande MA, Lee BL, Chambers HF: Treatment of right-sided $S$. aureus endocarditis in intravenous drug abusers with ciprofloxacin and rifampicin. Lancet 1989, 2:1071-1073.

46. Heldman AW, Hartert TV, Ray SC, et al:: Oral antibiotic treatment of right-sided staphylococcal endocarditis in injection drug users: prospective randomized comparison with parenteral therapy. Am J Med 1996, 101:68-76.
47. Alsip SG, Blackstone EH, Kirklin J, Cobbs CG: Indications for cardiac surgery in patients with active infective endocarditis. Am J Med 1985, 78(Suppl 6B):138-148.

48. Petterson G, Carbon C, and the Endocarditis Working Group of the International Society of Chemotherapy: Recommendations for the surgical treatment of endocarditis. Clin Microbiol Infect 1998, 4:3S34-3S46.

49.• Paone G, Silverman NA: Cardiac surgery in patients with HIV disease. In Advanced Techniques in Cardiac Surgery. Edited by Franco KL, Verrier ED. New York: BC Decker; 1999:20-24.

This chapter analyzes the short- and long-term prognosis of 108 HIV-infected patients who underwent cardiac surgery (1989-1997). Drug abuse was the etiologic factor in $76 \%$ of cases. Indications of surgery were IE in 84 patients, other valve diseases in 14, coronary artery disease in seven, and other in three patients.

50. Frater RWM: Surgical management of endocarditis in drug addicts and long-term results. J Cardiac Surg 1990, 5:63-67.

51. Brau N, Esposito RA, Simberkoff MS: Cardiac valve replacement in patients infected with the human immunodeficiency virus. Ann Thorac Surg 1992, 54:552-554.

52. Lemma M, Vanelli $P$, Beretta $L$, et al.: Cardiac surgery in HIV-positive intravenous drug addicts: influence of cardiopulmonary bypass on the progression of AIDS. Thorac Cardiovasc Surg 1992, 40:279-282.

53. Aris A, Pomar JL, Saura E: Cardiopulmonary bypass in HIV-positive patients. Ann Thorac Surg 1993, 55:1104-1108.

54. Carrel T, Schaffner A, Vogt P, et al.: Endocarditis in intravenous drug addicts and HIV infected patients: possibilities and limitations of surgical treatment. J Heart Val Dis 1993, 2:140-147.

55. Abad C, Cardenes MA, Jiménez PC, et al.: Cardiac surgery in patients infected with human immunodeficiency virus. Tex Heart Inst J 2000, 27:356-360.

56. Mathew J, Abreo G, Namburi K, et al.: Results of surgical treatment for infective endocarditis in intravenous drug users. Chest 1995, 108:73-77.

57. Arbulu A, Holmes RJ, Asfaw I: Surgical treatment of intractable right-sided endocarditis in drug addicts: 25 years' experience. J Heart Valve Dis 1993, 2:129-137.

58. Mestres CA, Chuquiure J, Claramonte X, et al: : Long-term results after cardiac surgery in patients infected with the human immunodeficiency virus type-1 (HIV-1). Eur J Cardio Thorac Surg 2003, 23:1007-1016.

From this study it was determined that the overall 10-year actuarial survival for all HIV patients undergoing major cardiac surgery is $58 \%$, and in the subgroup of HIV IVDA the survival extends up to $48 \%$.

59. Donaldson RM, Ross DN: Homograft aortic root replacement for complicated prosthetic valve endocarditis. Circulation 1984, 70:1178-1181.

60. Yankah AC, Klose H, Petzina R, et al.: Surgical management of acute aortic root endocarditis with viable homograft. A 13year experience. Eur J Cardiothorac Surg 2002, 21:260-267.

This is a very important paper providing information on the longterm performance of viable homografts when used for radical treatment of the infected aortic root.

61. Arbulu A, Thoms NW, Chiscano A, Wilson RF: Total tricuspid valvulectomy without replacement in the treatment of Pseudomonas endocarditis. Surg Forum 1971, 22:162-164.

62. Arbulu A, Asfaw I: Tricuspid valvulectomy without prosthetic replacement. Ten years of clinical experience. J Thorac Cardiovasc Surg 1981, 82:684-691.

63. Hughes CF, Noble N: Vegetectomy: an alternative surgical treatment for infective endocarditis of the atrioventricular valves in drug addicts. J Thorac Cardiovasc Surg 1988, 95:857-861.

64. Raman JJ, Bellomo RR, Shah PP: Avoiding the pump in tricuspid valve endocarditis vegetectomy under inflow occlusion. Ann Thorac Cardiovasc Surg 2002, 8:350-353.

65. Lange R, De Simone R, Buernschmitt $\mathrm{R}$, et al.: Tricuspid valve reconstruction, a treatment option in acute endocarditis. Eur J Cardiothorac Surg 1996, 105:320-326. 
66. Sons H, Dausch W, Kuh JH: Tricuspid valve repair in rightsided endocarditis. J Heart Val Dis 1997, 6:636-641.

67. Lai DT, Chard RB: Commissuroplasty. A method of valve repair for mitral and tricuspid endocarditis. Ann Thorac Surg 1999, 68:1727-1730.

68. Carozza A, Renzulli A, De Feo M, et al.: Tricuspid repair for infective endocarditis: clinical and echocardiographic results. Tex Heart Inst J 2001, 28:96-101.

69. De Vega NG: Selective, adjustable and permanent annuloplasty. An original technique for the treatment of tricuspid insufficiency. Rev Esp Cardiol 1972, 25:555-556.

70. Nakano K, Ishibashi-Ueda H, Kobayashi J, et al.: Tricuspid valve replacement with bioprostheses: long-term results and causes of valve dysfunction. Ann Thorac Surg 2001, 71:105-109.

71. Kaplan M, Kut MS, Demirtas MM, et al:: Prosthetic replacement of tricuspid valve: bioprosthetic or mechanical. Ann Thorac Surg 2002, 73:467-473.

72. Pomar JL, Mestres CA: The role of atrioventricular homograft valves in atrioventricular valve replacement. Asian Cardiovasc Thorac Ann 1996, 4:122-125.

73. Pomar JL, Mestres CA: Tricuspid valve replacement using a mitral homograft. Surgical technique and initial results. J Heart Valve Dis 1993, 2:125-128.

74. Pomar JL, Mestres CA, Paré JC, Miró JM: Management of persistent tricuspid endocarditis with transplantation of cryopreserved mitral homografts. J Thorac Cardiovasc Surg 1994, 107:1460-1463.

75. • Mestres CA, Miró JM, Paré JC, Pomar JL: Six-year experience with cryopreserved mitral homografts in the treatment of tricuspid valve endocarditis in HIV-infected drug addicts. J Heart Val Dis 1999, 8:575-577.

This report provides information on the mid-term results after tricuspid valve replacement with a cryopreserved mitral homograft.

76. Miyagishima RT, Brumwell ML, Jamieson WRE, Munt BI: Tricuspid valve replacement using a cryopreserved mitral homograft. J Heart Val Dis 2000, 9:805-808.

77. Nahass RB, Weinstein MP, Bartels J, Bocke DJ: Infective endocarditis in intravenous drug users: a comparison of human immunodeficiency virus type 1-negative and -positive patients. J Infect Dis 1990, 162:967-970.

78. Pulvirenti JJ, Kerns E, Benson C, et al.: Infective endocarditis in injection drug users: importance of human immunodeficiency virus serostatus and degree of immunosupression. Clin Infect Dis 1996, 22:40-45.
79.•• Ribera E, Miró JM, Cortés E, et al.: Influence of human immunodeficiency virus 1 infection an degree of immunosuppression in the clinical characteristics and outcome of infective endocarditis in intravenous drug users. Arch Intern Med 1998, 158:2043-2050.

This is the most important article that analyzes the influence of HIV-1 infection and the degree of immunosuppresion in the clinical characteristics and outcome of IE in IVDA.

80. Valencia ME, Guinea J, Soriano V, et al.: Estudio de $\mathbf{1 6 4}$ episodios de endocarditis infecciosa en drogadictos: comparación entre pacientes VIH positivos y negativos. Rev Clin Exp 1994, 194:535-539.

81. Manoff SB, Vlahov D, Herskowitz A, et al.: Human immunodeficiency virus infection and infective endocarditis among injecting drug users. Epidemiology 1996, 7:563-565.

82. Scheidegger C, Zimmerli W: Incidence and spectrum of severe medical complications among hospitalized HIV-seronegative and HIV-seropositive narcotic drug users. AIDS 1996, 10:1407-1414.

83. Wilson LE, Thomas DL, Astemborski J, et al.: Prospective study of infective endocarditis among injection drug users. J Infect Dis 2002, 185:1761-1766.

This study showed that IE incidence was higher among HIV-infected than HIV-seronegative IVDA, and multivariate analysis of HIV-

infected patients revealed an inverse association between IE and CD4 lymphocyte count

84. - Losa JE, Miró JM, del Rio A, et al.: Infective endocarditis not related to intravenous drug abuse in HIV-1 infected patients: report of eight cases and review of the literature. Clin Microbiol Infect 2003, 9:45-54.

This study found that the risk of IE is not increased in HIV-infected patients who do not abuse drugs.

85. Safaeian M, Wilson LE, Taylor E, et al.: HTLV-II and bacterial infections among injection drug users. J Acquir Immun Defic Syndr 2000, 24:483-487.

86. Robinson DJ, Lazo MC, Davis T, Kufera JA: Infective endocarditis in intravenous drug users: does HIV status alter the presenting temperature and white blood cell count? J Emerg Med 2000, 19:5-11.

87. Cicalini S, Forcina G, De Rosa FG: Infective endocarditis in patients with human immunodeficiency virus infection. J Infect 2001, 42:267-271. 